\title{
MTCI ACOUSTIC AGGLOMERATION PARTICULATE CONTROL
}

\section{Authors:}

R. R. Chandran

M. N. Mansour

Conf-9406131--14
A. W. Scaroni
G. H. Koopmann
J. L. Loth

\section{Contractor:}

Manufacturing and Technology Conversion International, Inc.

P. O. Box 21

Columbia, Maryland 21045

\section{Contract Number:}

DE-AC21-89MC26288

\section{Conference Title:}

Coal-Fired Power Systems 94 -- Advances in IGCC and PFBC

Review Meeting

\section{Conference Location:}

Morgantown, West Virginia

\section{Conference Dates:}

June 21-23, 1994

\section{Conference Sponsor:}

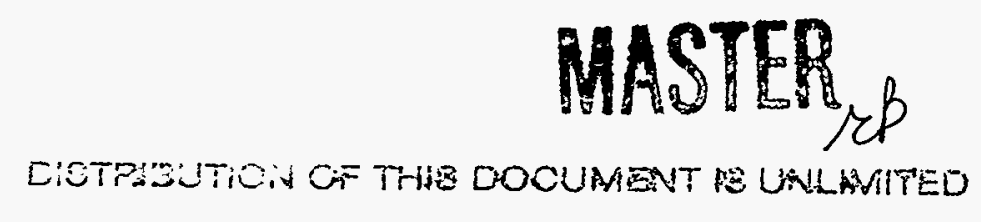

U.S. Department of Energy, Office of Fossil Energy, Morgantown Energy Technology Center 


\section{DISCLAIMER}

This report was prepared as an account of work sponsored by an agency of the United States Government. Neither the United States Government nor any agency thereof, nor any of their employees, makes any warranty, express or implied, or assumes any legal liability or responsibility for the accuracy, completeness, or usefulness of any information, apparatus, product, or process disclosed, or represents that its use would not infringe privately owned rights. Reference herein to any specific commercial product, process, or service by trade name, trademark, manufacturer, or otherwise does not necessarily constitute or imply its endorsement, recommendation, or favoring by the United States Government or any agency thereof. The views and opinions of authors expressed herein do not necessarily state or reflect those of the United States Government or any agency thereof.

This report has been reproduced directly from the best available copy.

Available to DOE and DOE contractors from the Office of Scientific and Technical Information, 175 Oak Ridge Tumpike, Oak Ridge, TN 37831; prices available at (615) 576-8401.

Available to the public from the National Technical Information Service, U.S. Department of Commerce, 5285 Port Royal Road, Springfield, VA 22161; phone orders accepted at (703) 487-4650. 


\section{DISCLAIMER}

Portions of this document may be illegible in electronic image products. Images are produced from the best available original document. 


\subsection{MTCI Acoustic Agglomeration Particulate Control}

\section{CONTRACT INFORMATION}

Contract Number

Contractor

Contractor Project Manager

Principal Investigators
DE-AC21-89MC26288

Manufacturing and Technology Conversion International, Inc. (MTCI)

P.O. Box 21

Columbia, MD 21045

(301) 982-1292

Ravi R. Chandran

Ravi R. Chandran

Momtaz N. Mansour

Alan W. Scaroni (Penn State U.)

- Gary H. Koopmann (Penn State U.)

John L. Loth (West Virginia U.)

METC Project Manager

Darren J. Mollot

Period of Performance

June 15, 1989 to June 1, 1995

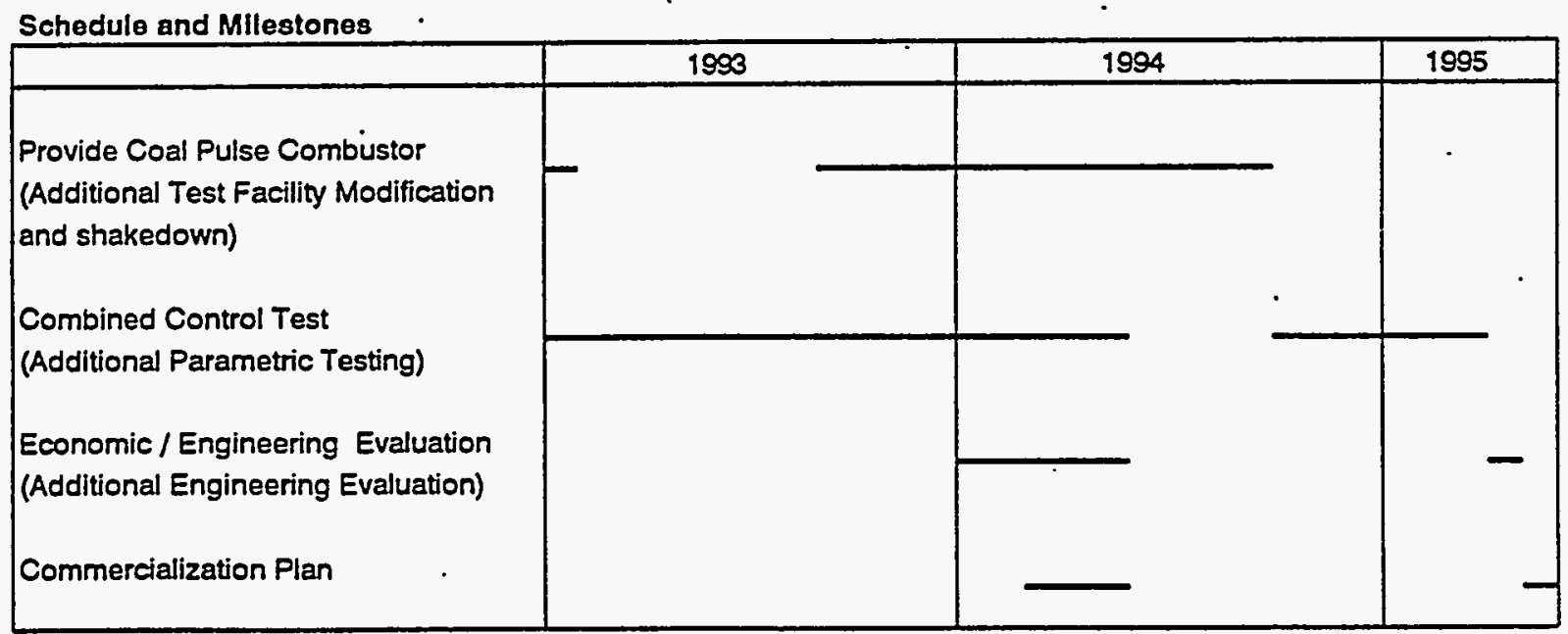

\section{OBJECTIVES}

The overall objective of this project is to demonstrate pulse combustion induced acoustic enhancement of coal ash agglomeration and sulfur capture at conditions typical of direct coal-fired turbines and PFBC hot gas cleanup. The goal of the program is to support the mission of the Department of Energy (DOE) for developing coal-fired combustion gas turbines and advanced PFBC systems. 
Specifically, the goals are to:

- Demonstrate the pulse coal combustion, ash agglomeration and sulfur capture,

- Achieve/Meet

- combustion efficiency $>99 \%$

- turbine tolerance criteria

- particulate loading in the 100 150 ppmw range

- particle size

$<10$ microns with $99 \%$

$<3$ microns

- $\mathrm{NO}_{\mathrm{x}} @ 15 \% \mathrm{O}_{2}$

$<125 \mathrm{ppm}$

$--\mathrm{SO}_{2} @ 15 \% \mathrm{O}_{2}$

$<75 \mathrm{ppm}$

- New Source Performance Standards

- $\mathrm{SO}_{2}<1.2 \mathrm{lb} / \mathrm{MMBtu}$

- $\quad \mathrm{NO}_{\mathrm{x}}<0.6 \mathrm{lb} / \mathrm{MMBtu}$

- particulates

$<0.03 \mathrm{lb} / \mathrm{MMBtu}$

\section{BACKGROUND INFORMATION}

Growing concern over global warming, dwindling environmental quality, accelerated waste generation rate, and dependence on foreign oil has spawned an interest in and the need for advanced energy technologies in general and advanced combustion technologies in particular. This, together with the interest in increasing the utilization of coal, entails the development of innovative concepts which promise higher combustion efficiency, higher sulfur capture efficiency, lower $\mathrm{NO}_{\mathrm{x}}$ emissions, lower particulate emissions, and greater fuel flexibility. The advanced combustion technologies currently under demonstration include Fluidized Bed Combustion (FBC), Staged Slagging Combustion (SSC), and Limestone Injection Multistage Burning (LIMB).
While these technologies promise lower $\mathrm{SO}_{2}$ and $\mathrm{NO}_{\mathrm{x}}$ emissions compared to conventional technologies, each possesses one or more of the following limitations:

- Operates either in the combined cycle format but at a lower peak cycle temperature (e.g., $1550^{\circ} \mathrm{F}$ rather than at $\sim 2300^{\circ} \mathrm{F}$ ) or at atmospheric system pressure and therefore not in the combined-cycle format. This results in lower overall cycle thermal efficiency and consequently higher specific fuel consumption and typically higher emissions levels $\left(\mathrm{CO}_{2}, \mathrm{CO}\right.$, $\mathrm{SO}_{2}, \mathrm{NO}_{x}$, and particulate) per pound of coal burned.

- Operates in the slagging mode which poses difficulty with regard to design, reliability, material selection, compliance with emissions standards in the absence of downstream particulate collection equipment, and economics.

- Requires barrier filters to control particulate emissions which pose concerns regarding durability, economics, and limited operating range.

- Requires specially prepared sorbents or some process enhancement to improve calcium utilization and achieve $90 \% \mathrm{SO}_{2}$ retention and this significantly increases the operating cost of the unit.

In response to this challenge, MTCI has developed an advanced compact pulse combustor island for direct coal-firing in combustion gas turbines. This combustor island comprises a coalfired pulse combustor, a combined ash agglomeration and sulfur capture chamber (CAASCC), and a hot cyclone (Figure 1). In the MTCI proprietary approach, the pulse combustioninduced high intensity sound waves improve sulfur capture efficiency and ash agglomeration. The resulting agglomerates allow the use of 
commercial cyclones and achieve very high particulate collection efficiency.

Many investigations have confirmed the ability of acoustic fields to agglomerate fly ash to increase particle size. However, the majority of this work focused on the agglomeration of unimodal distributions of fine aerosols which were not fully representative of the conditions within a gas turbine combustor utilizing standard grind pulverized coal or coal-water mixtures, particularly in conjunction with lime sorbent injection processes. Therefore, the conclusions drawn from experimental and theoretical investigations to date using fine unimodal distributions, such as the optimum acoustic sound pressure levels and frequency, may not be valid as applied to the MTCI coal-fired gas turbine technology.

In the MTCI proprietary approach, sorbent particles are injected into a gas stream subjected to an intense acoustic field. The acoustic field serves to improve sulfur capture efficiency by enhancing both gas film and intra-particle mass transfer rates. In addition, the sorbent particles act as dynamic filter foci, providing a high density of stagnant agglomerating centers for trapping the finer entrained (in the oscillating flow field) fly ash fractions. The fly ash fractions have particle sizes which fall primarily in the range from less than 1 to 20 microns. Therefore, by introducing sorbent particles which are primarily concentrated in the size range from 20 to 80 microns, a bimodal distribution is created. The bimodal distribution offers several advantages. First, by increasing the density (in the gas) of large stagnant trap centers, an accelerated agglomeration rate can be achieved. Second, agglomeration can be efficiently performed at a significantly lower acoustic frequency range compared to unimodal distributions containing only finer fly ash fractions.

The effectiveness of particle agglomeration at low frequencies is extremely significant. The rate of agglomeration is strongly influenced by the acoustic intensity level. Since low frequencies are attenuated less than high frequencies, lower frequency operation is anticipated to be more effective. Furthermore, low frequencies are not expected to affect performance of turbine blades, while frequencies in the $\mathrm{kHz}$ range may couple into the system's natural frequencies. Finally, the cut-off particle diameter for $50 \%$ entrainment increases with a decrease in frequency and therefore lower frequency operation results in the entrainment of a larger proportion of a given particle feed size distribution and places less constraint on the upper limit for particle growth.

The major advantage of the MTCI combustor island shown in Figure 1 is the ability to use standard grind, unbeneficiated or partially beneficiated coal as fuel. It offers the following additional benefits:

- Pulse combustion provides for a relatively high volumetric heat release rate and high combustion efficiency in a shorter residence time. This gives rise to a compact combustor.

- The pulse combustor is an inherently low $\mathrm{NO}_{\mathrm{x}}$. burner and therefore $\mathrm{NO}_{x}$ emissions are low.

- While a conventional steady flow combustor results in pressure loss, the pulse combustor provides for a combustion-induced pressure boost. The net pressure gain is therefore significant and offers the potential for higher specific power output or lower specific fuel consumption.

- Employs sonic-enhanced coal ash agglomeration and dry ash rejection. This avoids the need for slagging mode of operation which poses difficulty with regard to design, reliability, material selection, compliance with emissions standards, and economics. Ash agglomeration allows the use of conventional cyclones to achieve very high particulate 
collection efficiency and eliminates the need for barrier filters which pose concerns regarding durability and economics.

- Efficient in-situ sulfur and alkali capture in sonic-enhanced mode.

\section{PROJECT DESCRIPTION}

The overall objectives of this project are to experimentally develop the basic design framework for scale-up of this technology and to experimentally characterize a laboratory-scale gas turbine combustor island. to:

The specific objectives of this program are

- Perform system shakedown and parametric testing;

- Conduct applied studies for the development of a combined acoustic agglomeration and sulfur capture model and an aerodynamic analysis to establish the aerovalve design data base;

- Conduct engineering and economic evaluations of the system; and

- Develop a design code for combustor island scale-up.

A team has been formed with MTCI as the prime contractor and Penn State University (PSU) and West Virginia University (WVU) as subcontractors to MTCI. MTCI is focusing on hardware development and system demonstration, PSU is investigating and modeling acoustic agglomeration and sulfur capture, and WVU is studying aerovalve fluid dynamics.

\section{Apparatus}

To demonstrate proof-of-concept, a laboratoryscale bimodal test facility has been designed, fabricated, and integrated for elevated pressure (4 atm.) operation at MTCI (Figure 2). It incorporates an advanced tailpipe-agglomeration chamber interface configuration, a coal preheating arrangement, a refractory-lined cyclone to simulate hot gas cleanup, and elaborate instrumentation and controls to enable complete process characterization and safe operation. The test facility comprises the following components/ subsystems:

- Coal and sorbent feed system.

- Air and natural gas supply system.

- Pulse combustor.

- Acoustic agglomeration and sulfur capture chamber.

- Refractory-lined cyclone.

- Fuel preconditioner.

- Heat exchanger.

- Pressure letdown valve.

- Baghouse.

- Steam circuit.

- Cooling water circuit.

- Instrumentation and controls.

Initial tests were performed with one cyclone (primary cyclone) on-line. The design velocity for this cyclone was kept modest (40 to $50 \mathrm{ft} / \mathrm{s}$ ) to reduce potential agglomerate breakup during transit. This, however, reduced the particulate capture efficiency so that some $10 \mu \mathrm{m}$ 
size particles were leaving with the cyclone exit flue gas. Therefore, a secondary cyclone was added (as shown in Figure 2) to enhance overall solids capture efficiency.

\section{System Tests and Results}

At MTCI, system shakedown tests were initially conducted at pressures of 2 and $3 \mathrm{~atm}$. with natural gas and pulverized coal (Seacoal Pittsburgh No. 8). After verification of satisfactory system operation, 27 screening tests have been performed. The system has been in operation for about 193 test hours.

The parameters varied include pulverized sorbent types, sorbent injection location and $\mathrm{Ca} / \mathrm{S}$ molar feed ratio. The sorbent types examined include a dolomite (Dolofil by Pfizer), a limestone (Linden Falls), a precalcined lime (Annville by Wimpey Minerals), a pulse combustor calcined and classified (PCC) dolomite (Pfizer Dolofil), and a PCC lime (Annville by Wimpey Minerals). of:

Tests have been performed with injection

- Coal into the pulse combustion chamber and no sorbent injection,

- Premixed coal and sorbent (dolomite or limestone) into the pulse combustion chamber (P.C.),

- Coal into the pulse combustion chamber and sorbent (dolomite, lime, mixture of lime and Baltimore Gas and Electric power plant fly ash, cold air classified lime, PCC dolomite and PCC lime) into the inner section of the agglomeration chamber (A.C.).

The PCC dolomite and PCC lime were generated in the MTCI laboratory-scale pulsed atmospheric fluidized combustion system which integrates a pulse combustor with a bubbling fluidized bed.

The reader is referred to an earlier paper [1] for test results from the initial test series. The overall test results indicated the following:

- Stable pulse combustor operation was achieved with a variation in firing rate from 1.67 $\mathrm{MMBtu} / \mathrm{hr}$ to $2.52 \mathrm{MMBtu} / \mathrm{hr}$ at $3 \mathrm{~atm}$. system pressure.

- The pressure oscillations were robust and the sound pressure level (SPL) varied from 174 to $186 \mathrm{~dB}$ with an increase in firing rate.

- The combustion efficiency exceeded $99 \%$.

- The sulfur capture efficiency ranged from 38 to $98.5 \%$. Calcium utilization was the highest with dolomite followed by lime and then by limestone. Limestone was pretty good in capturing sulfur (77\%) at low firing rate but inferior (38\% sulfur capture) at medium firing rate probably due to sintering. Sulfur capture exhibited an increase with $\mathrm{Ca} / \mathrm{S}$ feed ratio for $\mathrm{PCC}$ dolomite and PCC lime injection into the A.C. (see Figure 3). The calcium utilization was low due probably to the high operating temperature $\left(2000-2200^{\circ} \mathrm{F}\right)$ in the A.C.

- $\mathrm{NO}_{\mathrm{x}}$ emissions were in the 82 to $200 \mathrm{ppm}$ range when corrected to $15 \% \mathrm{O}_{2}$ (Figure 4). $\mathrm{NO}_{\mathrm{x}}$ emissions tended to increase with dolomite feed rate corroborating the catalytic effect of calcined dolomite on $\mathrm{NO}_{x}$ formation reactions. With PCC lime injection into A.C., the $\mathrm{NO}_{\mathrm{x}}$ emissions did not increase from the base case (no sorbent injection) level and remained below the $125 \mathrm{ppm} @ 15 \% \mathrm{O}_{2}$ target for turbine tolerance.

- The solids loading in the cyclone exit flue gas ranged from $23 \mathrm{ppmw}$ (with two cyclones) to $450 \mathrm{ppmw}$ (with one cyclone). The highest 
loading was obtained with dolomite injection into the P.C. and this is attributed to particle fragmentation and fines generation in the high heating rate environment of the pulse combustor. Penn State University (PSU), in an independent study, similarly found increasing decrepitation with an increasing magnesium oxide content. The high purity limestone (Linden Falls) was tested based on the recommendation of PSU and it also was found to decrepitate albeit to a lesser extent than dolomite. The injection of lime into the agglomeration chamber was therefore attempted and the test results indicate the merit of that option. With one cyclone on-line, the cyclone exit flue gas solids loading was below $150 \mathrm{ppmw}$ and within the target goal for gas turbine particulate tolerance. With one cyclone on-line, the baghouse catch indicated about $30 \%$ by weight of particles exceeding 3 microns in size. Turbine tolerance criteria require less than $1 \%$ by weight of particles exceeding 3 microns in size and therefore a secondary, high efficiency cyclone was added to the system. Ideally, this secondary cyclone should be located downstream of the primary cyclone and upstream of the heat exchanger. However, due to such considerations as space constraints leading to repiping difficulties and cost factors, it was decided to locate the secondary cyclone downstream of the heat exchanger but upstream of the pressure letdown valve. With two cyclones on-line, coal firing and no sorbent injection, the cyclone exit solids loading dropped to 32 to 44 ppmw range (see Figure 5). With PCC dolomite injection, the cyclone exit solids loading was higher (72 ppmw) possibly due to sorbent fines generation. With PCC lime injection, the cyclone exit solids loading dropped to the 23 to $27 \mathrm{ppmw}$ range (see Figure 5) which is good enough- to meet the New Source Performance Standards (NSPS).
- The particle size distributions for the primary and secondary cyclone catch material and the secondary cyclone exit solids are shown in Figure 6. The data correspond to the coalfired test with no sorbent injection. The secondary cyclone exit stream was isokinetically sampled with a pre-calibrated cascade impactor. The two cyclone catch material were sized by the BAHCO method. The d50 cut sizes for the three streams are also shown in Figure 6. There seems to be room for improvement of the second cyclone performance and thereby decrease both the larger size ( $>3$ microns) particle population and the total solids loading in the second cyclone exit stream. For example, the "core separator" concept of LSR Technologies, Inc. [2] could be used in lieu of the two cyclones to achieve higher particulate collection efficiency.

- The size distributions of the particles collected by the cascade impactor in the case of tests without and with PCC lime injection are shown in Figure 7. The particle sizes are relatively larger and the quantities/weights are smaller for the case of lime injection in comparison to that for no sorbent injection. This is further evidence for the effectiveness of bimodal agglomeration. Note that the ash generated from coal combustion typically has a bimodal particle size distribution and agglomerates in the presence of an acoustic field even without sorbent injection. For example, based on literature data [3], about $30 \%$ by weight of ash generated in conventional combustion corresponds to a size below 6.4 microns. Assuming a linear variation in cyclone collection efficiency up to 6.4 microns and $100 \%$ capture efficiency beyond that size, a first order estimate for solids loading in the flue gas corresponding to the combustion conditions of Figure 6 is 429 ppmw. The measured loading was in the 32 to 44 ppmw range indicating the advantages of acoustic agglomeration. Let the 
acoustic agglomeration enhancement factor (AAEF) be defined as:

$$
\mathrm{AAEF}=100(1-\mathrm{TMA} / \mathrm{TMO})
$$

where TMO is the mass loading at the exit of the cyclone without acoustic pretreatment and TMA is the mass loading at the cyclone exit with acoustic pretreatment. Then AAEF for the no sorbent and lime injection cases turn out on average to be 91 and $94 \%$, respectively. This is a substantial improvement and verifies the merit of pulse combustion-induced bimodal agglomeration.

- The measured emissions of $\mathrm{SO}_{2}, \mathrm{NO}_{\mathrm{x}}$ and particulates with PCC lime injection were all below the levels stipulated by NSPS as shown in Figure 8.

- CO and total hydrocarbon (THC) emissions were generally below 10 and $5 \mathrm{ppm}$ respectively @ 3\% $\mathrm{O}_{2}$.

The test results obtained from the MTCI laboratory-scale combustor island are encouraging and meet gas turbine tolerance criteria and New Source Performance Standards.

\section{PSU STUDY}

The objective of the work being conducted at Penn State University is to provide scientific verification of the MTCI pulse combustion technology in the areas of sulfur capture and bimodal agglomeration. The project consists of two parts: 1) investigation of the fundamental behavior of sorbents under pulse conditions, particularly the effect of rapid sorbent particle heat-up and the presence of an acoustic field on calcination and sulfation, and 2) a fundamental investigation of acoustic bimodal agglomeration.
The presence of an acoustic field within the combustion environment influences the mass transfer of $\mathrm{SO}_{2}$ to particle surfaces and the movement of particles themselves within the gas stream. The result is an enhancement in the rate and extent of sulfation of limestone in the system. Mitigation of $\mathrm{SO}_{2}$ from the gases produced during the combustion of fossil fuels is necessary given the new $\mathrm{SO}_{2}$ emission standards. In addition, the agglomeration of very fine particles is necessary for the application of this technology to produce hot combustion gases for gas turbines. Gas turbines have a very low tolerance level for particles within the gas stream. Removal of the coarser size fractions can be accomplished by current technology; however, removal of micron and submicron particles is more difficult. Agglomeration of the micron size ash and sulfated calcine particles forms larger particles that can be removed more efficiently by conventional particle collection technology.

Calcination and Sulfation Studies and PCGC-2 Modeling

Experimental studies in the area of calcination and sulfation have shown that under high heating rates the fragmentation of sorbents is influenced by the sorbent type, particle size and particle temperature. Sorbent type was the most important factor. Dolomites and limestones containing high levels of magnesium fragment to a greater extent during heating producing significantly finer calcine than high purity limestones.

The extent of calcination of sorbents was relatively insensitive to particle size; however, the extent of sulfation was affected by particle size. Particle size affects heat transfer such that smaller particles calcine at a slightly greater rate than larger particles (Figure 9). The extent of sulfation was related to particle size as shown in Figure 10. An increase in the $\mathrm{S} / \mathrm{Ca}$ molar ratio of 26 to $32 \%$ was observed for a dolomite and a 
high purity limestone, respectively, when the average particle size was decreased from 89 to $45 \mu \mathrm{m}$. On the basis of sorbent utilization the performance of lower purity stones was not significantly different than that of high purity stones. This may have implications regarding sorbent selection for the MTCI pulse combustor system due to the stringent requirements for low particle loading of fines.

The experimental data from the calcination and sulfation studies was used to modify an existing combustion model, i.e., PCGC-2. PCGC-2 can model gaseous turbulent diffusion flames and pulverized coal combustion. PCGC-2 has been successfully modified to include mechanisms that define the calcination, sintering and sulfation process. Empirically obtained rate equations were used to model the processes of calcination and sulfation. A shrinking core model was used to model calcination. Processes influencing sulfation include: the rate of calcination, product layer diffusivity, pore diffusion, external heat and mass transfer. Pore diffusion dominates for large particles, i.e., $100 \mu \mathrm{m}$, whereas product layer diffusion dominates for submicron size particles. Heat and mass transfer effects are more limiting in larger particles. The model assumes that sulfation is irreversible. Sulfur release during combustion is assumed to be proportional to the coal weight loss and local instantaneous equilibrium chemistry is assumed for the conversion of sulfur to sulfur dioxide.

The model was fitted to the experimental data predicting the calcination and sulfation of particles 45, 63, and $89 \mu \mathrm{m}$ in size (Figures 9 and 10). The model further predicts that the extent of sulfation increases with increasing sound pressure level due to the increase in mass transfer coefficients (Figure 11). Modeling by PCGC-2 shows that an acoustic field generates large relative velocities between the particles and the gas stream. The increase in slip velocity between the particle and gas stream increases the heat and mass transfer to and from the particles. The increase in the mass transfer coefficient, i.e., Sherwood number, with increasing sound pressure is shown in Figure 11. An increase in the Sh number results in an increase in the rate at which $\mathrm{SO}_{2}$ reaches the surface of the calcine, thereby increasing the rate of sulfation. In addition, highly porous calcines $(\epsilon=0.5)$ show a greater increase in the extent of sulfation than less porous calcines $(\epsilon=0.15)$, i.e., approximately $12 \%$ at higher sound pressure levels (Figure 12).

Another benefit of the presence of the acoustic field is due to the agglomeration of small particles to form larger agglomerates. Calcine particles that agglomerate experience a greater rate of diffusion of $\mathrm{SO}_{2}$ to the calcine surfaces than smaller calcine particles. The Sh number is proportional to the mass transfer coefficient which determines the rate of $\mathrm{SO}_{2}$ diffusion to the particle. Therefore, the rate of $\mathrm{SO}_{2}$ diffusion to the surface of smaller particles that make up an agglomerate is greater than the rate of $\mathrm{SO}_{2}$ diffusion to individual small particles.

\section{Acoustic Agglomeration}

This work has provided new insight into the interaction mechanisms between small particles under the influence of a strong acoustic field. These mechanisms are associated with what is referred to as acoustic agglomeration caused by the relative motion and collisions between particles in a high intensity sound field. The agglomeration process has potential use in air pollution control to enhance the performance of conventional particle filtering devices. A number of existing acoustic agglomeration models are reviewed and presented graphically in Figure 13. A quantitative analysis of the proposed theories was conducted with parameters representing those of the physical experiments. The evaluation of the different models leads to the conclusion that mutual scattering interaction, an effect proposed as an important agglomeration volume refill 
factor, does not contribute significantly to the agglomeration process if gravitational effects are included in the computations. On the other hand, hydrodynamic effects due to asymmetric flow fields around the particles generate significant particle attraction in the direction of the acoustical axis (Figure 14). This so-called "acoustic wake effect" is shown to contradict another mechanism referred to as the mutual radiation pressure interaction. A comparative analysis of the two effects suggest that the competing interaction forces might lead to "pseudo" agglomerates, i.e., pairs of particles held together by an acoustically induced captive force field.

To evaluate these findings, experimental analysis were carried out with a small-scale observation chamber using a CCD camera in conjunction with a high resolution video system. A homogenous acoustic velocity field is generated by two rectangular, flat-membrane loudspeakers which comprise two opposing walls in the observation chamber. Glass microspheres (diameters 8,1 and $22.1 \mu \mathrm{m}$ ) and quartz particles (diameter $<50 \mu \mathrm{m})$ are used for the observation of interaction and agglomeration trajectories under the influence of an intense acoustic velocity field $(1.2-0.53 \mathrm{~m} / \mathrm{s}$ at $400-900 \mathrm{~Hz})$. The recorded digitized images show a number of similar-sized particles which come together forming larger agglomerates. It is proposed that similarly sized particles first agglomerate to form larger clusters. These larger clusters then find particles of similar size forming larger agglomerates. This process is enhanced at higher sound frequency levels and pressure levels. For dissimilar particle sizes, the particles displayed an axial change of direction resulting missed collisions. In general, this behavior did not lead to particle agglomerations. The experimental evidence suggests the conclusions given in Table 1 regarding the various acoustic agglomeration models.

\section{WVU STUDY}

The quality of an aerovalve is expressed in terms of diodicity (DIO), defined as the ratio of forward mass flow to reverse mass flow. Thus, diodicity is a strong function of the aerovalve: geometry, size, inlet pressure and temperature and the type of gas used as well as the exit back pressure. The aerovalve operates in a non-steady flow field inside the pulse combustor. The length of the aerovalve $\left(\mathrm{L}_{\mathrm{a}}\right)$ is at lease ten times shorter than the length of the combustor tailpipe $\left(L_{2}\right)$, the latter controls the combustion pulse frequency. The pulse frequency is approximately equal to $f_{v}=1 / 2 a / L_{l}$, where (a) is the speed of sound. Thus the resonance frequency of the short aerovalve by itself is about ten times higher than the combustion pulse frequency. Therefore, non-steady aerodynamic effects are negligible and a quasisteady state flow analysis can be applied to compute its mass flow rate as a function of pressure differential. This justifies aerovalve diodicity testing using steady flow tests in both the forward and the reverse flow directions. During a pulse combustion cycle, the peak as well as the mean forward and reverse mass flow rates can be calculated by integrating the instantaneous mass flow rates based on pressure as a function of time for any given wave form.

Besides the need for high diodicity and small size, the aerovalve must also have low total pressure loss in forward flow. Next, the pressure differential, where the forward flow starts to choke and the diodicity drops off, should be high. The aerovalve must be easy to manufacture and to keep clean.

The MTCI aerovalves tested incorporate a venturi-type geometry with a rapid contraction to a throat area $\left(\mathrm{A}_{\mathrm{th}}\right)$ with a sharp angle transition to a small angle diffuser where the flow expands to area $\left(A_{2}\right)$. Reverse flow is unable to negotiate the sharp turn at the throat and therefore separates at 
the throat without any diffusion type pressure recovery.

For the cold flow ideal subsonic isentropic flow venturi-type aerovalve, the diodicity (DIO) equals the venturi area ratio $\bar{A}=A_{2} / A_{t h}$. This can be explained as follows. In this case there is no loss in total pressure and the flow adjusts itself such that the exit static pressure equals the back pressure. Thus the exit total to static pressure ratio and exit Mach number are identical for both forward and reverse flow. In cold flow the total temperature for the flow in both directions is the same and thus also the exit velocity and densities are the same. The forward to reverse mass flow ratio equals then the forward flow to reverse flow exit area ratio which is $\bar{A}$.

For hot flow, the temperature ratio $\left(T_{r}\right)$ between the hot combustion chamber temperature and that of the cold air intake plenum further increases the diodicity. Because the exit Mach number is the same with identical pressure ratio, the exit static temperature ratio will also be equal $T_{r}$, thus the exit density ratio is equals $1 / T_{r}$ and the exit speed of sound ratio equals $T_{r}^{1 / 2}$ and the exit velocity ratio as well. Consequently, the forward to reverse mass flow ratio equals $\overline{\mathrm{A}} \mathrm{T}_{\mathrm{r}}^{1 / 2}$ (see Figure 15). The higher the operating temperature difference between the pulse combustion chamber and the air inlet plenum, the higher the diodicity and the wider the dynamic range. The diodicity, however, becomes lower and poses a problem for gas turbine and vitiated air pulse combustion modes of operation. Further development is therefore needed for superior performance in these cases.

Experiments were conducted in a cold flow test facility at room temperature. Figure $\mathbf{1 6}$ is a plot of the mass flow through an aerovalve of both forward and reverse flow against $\triangle P$ as measured by the differential manometer. For a $\Delta \mathrm{P}$ of $6 \mathrm{psi}$, one can see where both the forward and reverse flows choke. This condition restricts both flow cases to the same throat sonic velocity but the diffuser losses in forward flow actually reduces the density and thus the forward mass flow to less than the reverse mass flow value at the same pressure drop. This makes the diodicity slightly less than one. It is a condition that does not occur in actual operation but it gives a feel of how the diffuser losses can play a significant role in the aerovalve performance.

A quasi-steady flow analysis was also performed using a numerical code. Diodicity of the aerovalve was determined as a function of area ratio, temperature ratio, and pressure ratio. With an increase in pressure ratio, the forward flow was found to choke first and the reverse flow later. This tends to place a limit on the pulse combustor pressure rise/dynamic pressure/SPL that can be achieved. WVU and MTCI have formulated an advanced aerovalve concept to delay the onset of forward flow choking, achieve high diodicity, and permit ease of fabrication.

\section{FUTURE WORK}

MTCI has formulated an alternate advanced concept to meet the DOE mission-oriented criteria for performance, emissions and economics. Additional investigations are planned at MTCI, PSU and WVU to expand the combined control tests and further develop the MTCI advanced coal-fired gas turbine combustion technology. 


\section{REFERENCES}

1. Mansour, M.N. and R.R. Chandran, "Sonic Enhanced Ash Agglomeration and Sulfur Capture, Proc. Tenth Annual International Pittsburgh Coal Conference, Pittsburgh, PA, Sept. 20-24, 1993, pp. 190-195.

2. Smolensky, L.A. and B.H. Easom, "Particulate Control for Coal-Fueled Diesel Engine Exhaust," Proc. of the Joint Contractors Meeting: FE/EE Advanced Turbine Systems Conference, FE Fuel Cells and Coal-Fired Heat Engines Conference, DOE/METC-93/ 6132 (NTIS/DE93011308), August 1993, pp. 327-333.

3. Diehl, R.C., P.J. Loftus, D.B. Stickler, and P.W. Pillsbury, "Emissions Control in a CoalFueled Gas Turbine Slagging Combustor for Utility Applications," Proc. Seventh Annual Coal-Fueled Heat Engines and Gas Stream Cleanup Systems Contractors Review Meeting, DOE/METC-90/6110 (NTIS/DE90000480), March 1990, pp. 113-122. 


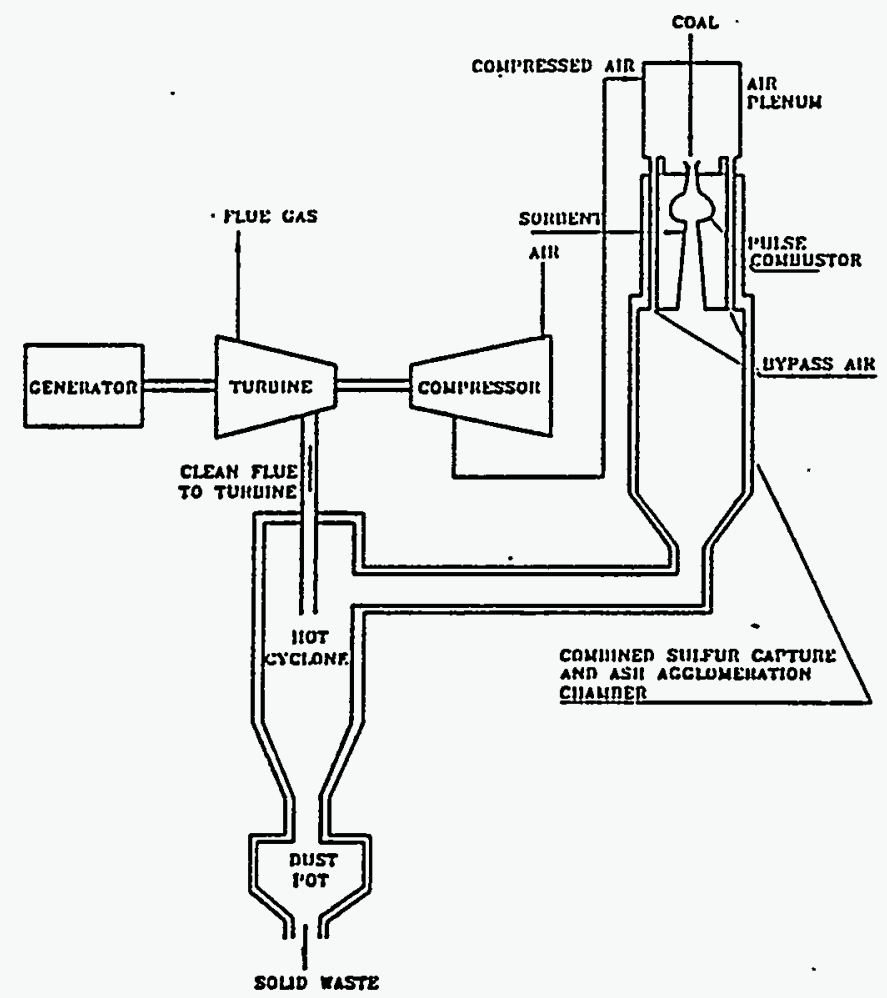

Figure 1. MTCI's Combustor Island for Direct Coal-Fired Gas Turbine Application

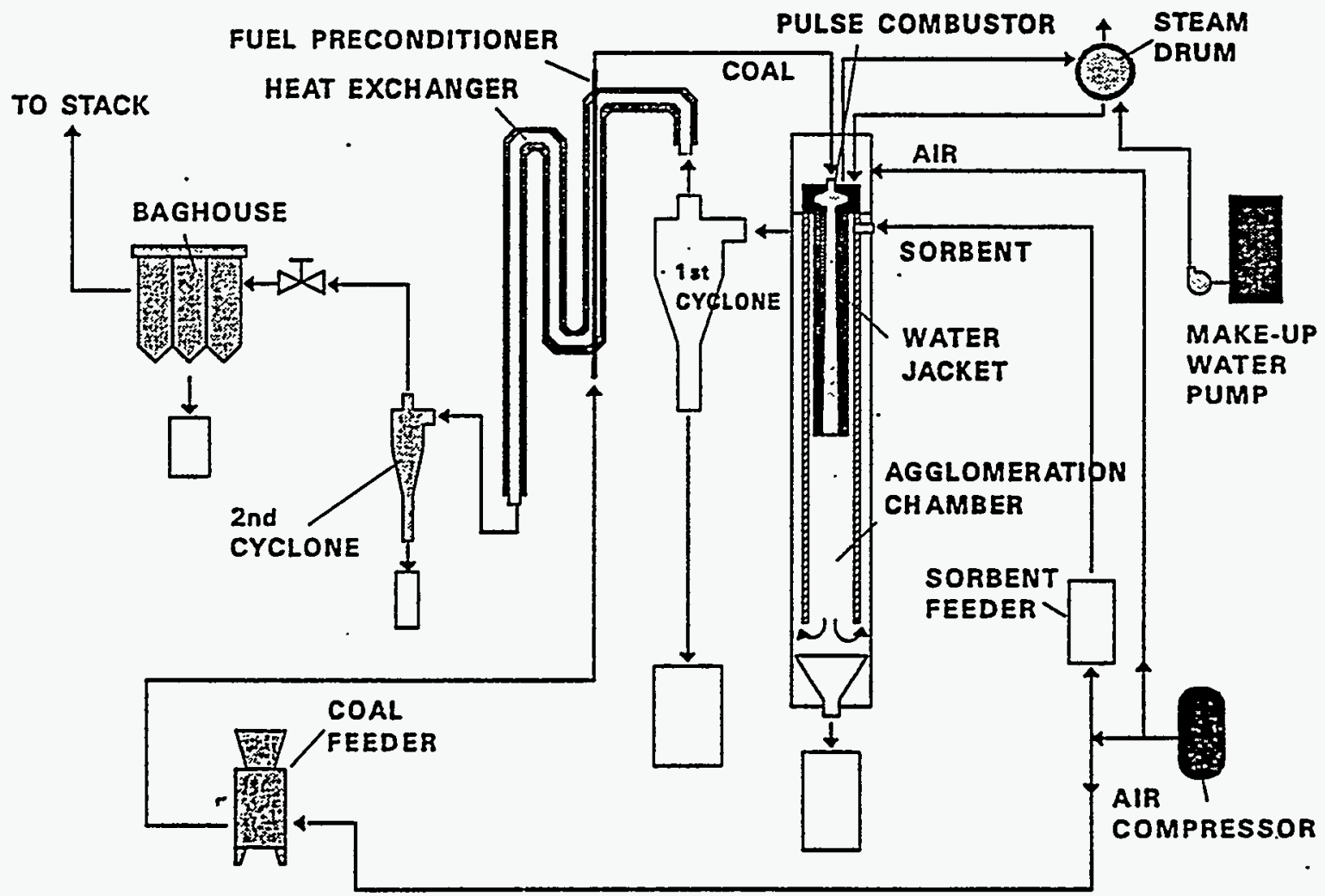

Figure 2. Schematic of the Test System 


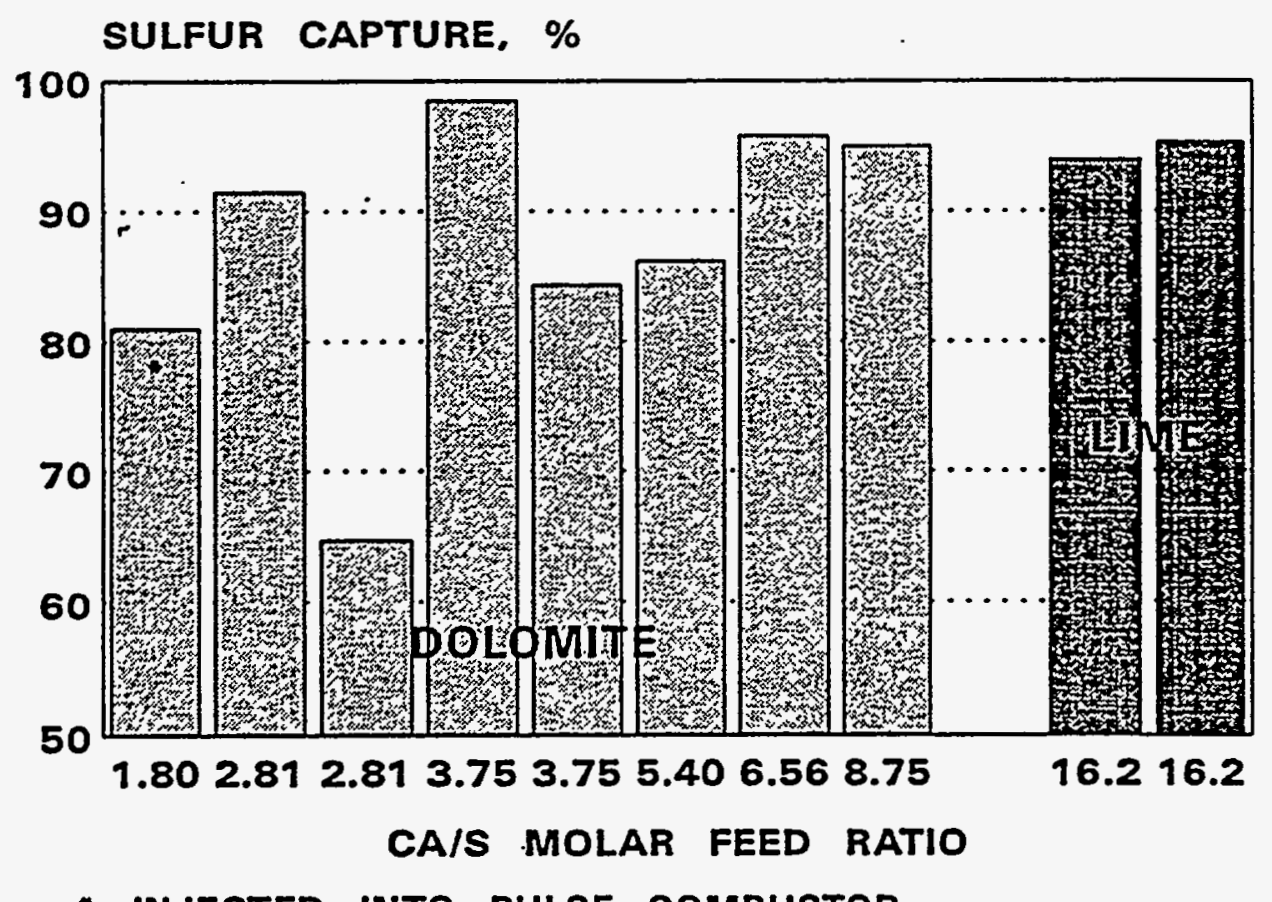

- INJECTED INTO PULSE COMBUSTOR

Figure 3. Sulfur Capture Efficiency

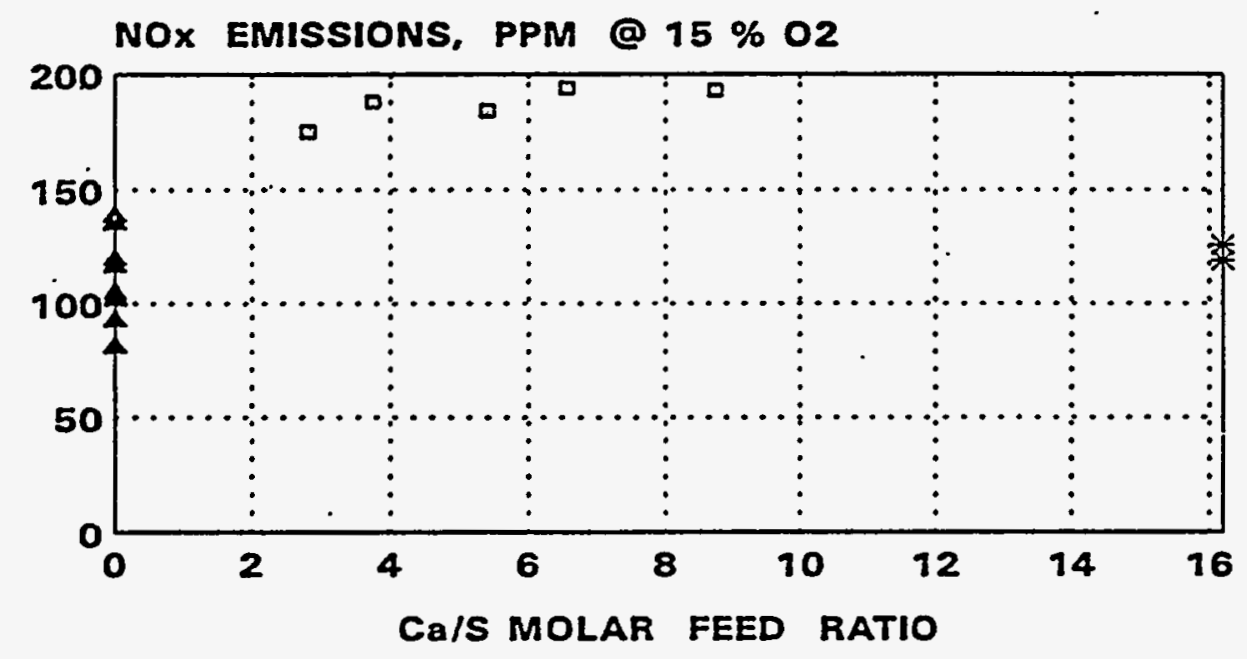

\section{- DOLOMITE * LIME ^ NO SORBENT}

Figure 4. $\mathrm{NO}_{\mathrm{x}}$ Emissions With Coal and Sorbent Feed 


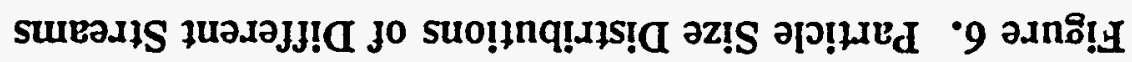

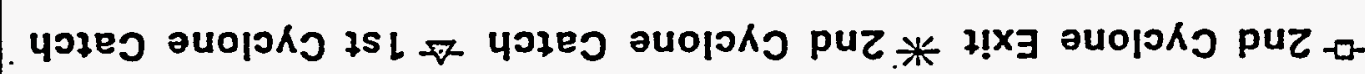

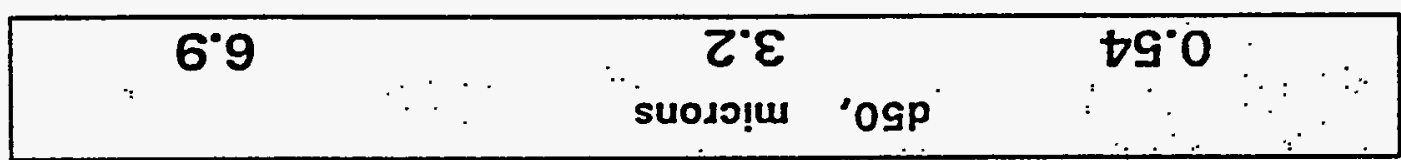

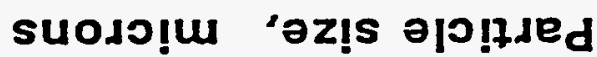

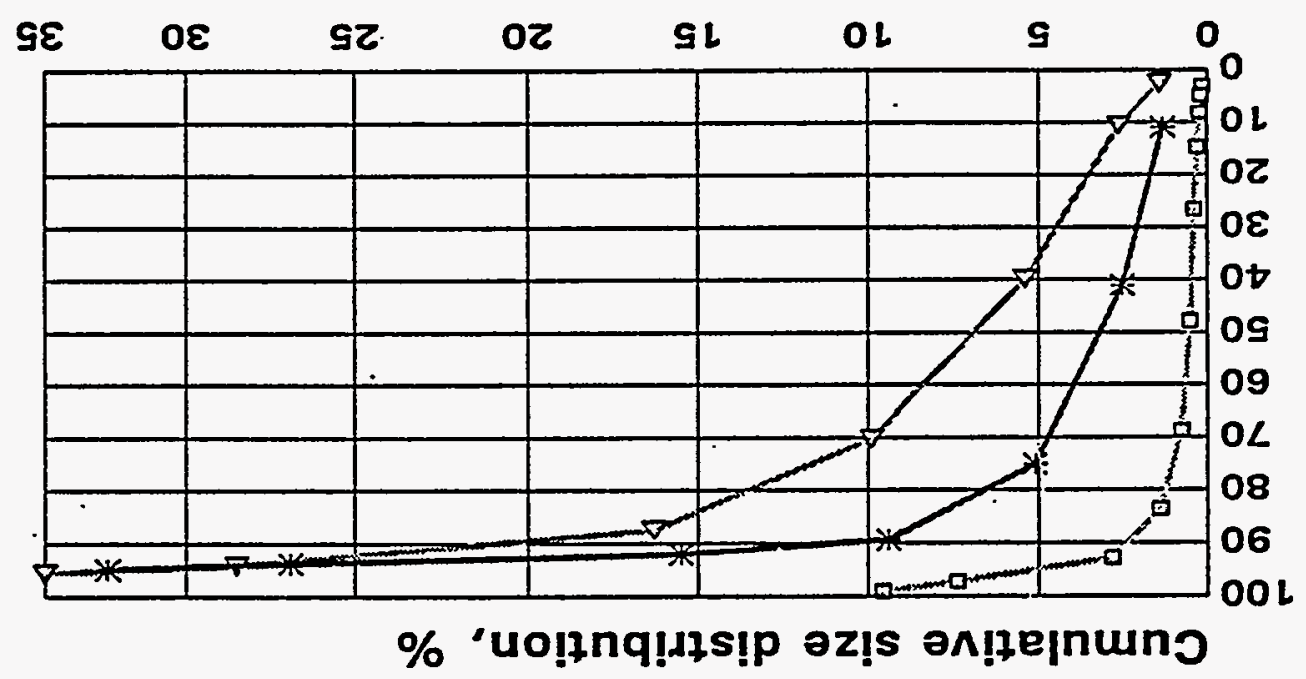

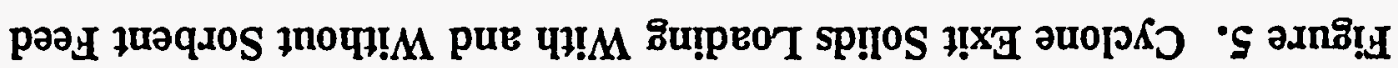

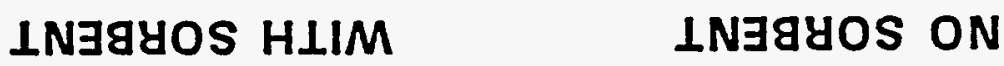

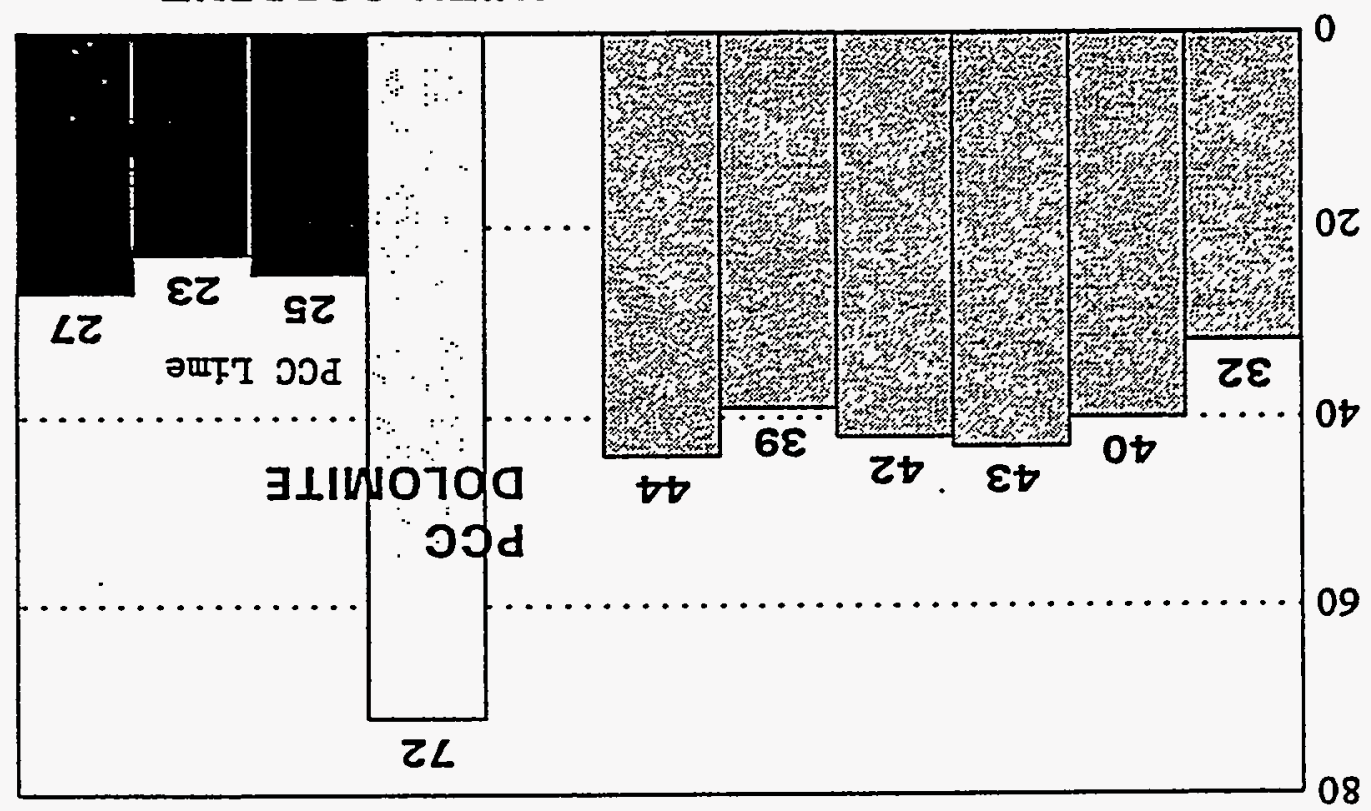


Differential weight, $\mathbf{m g}$

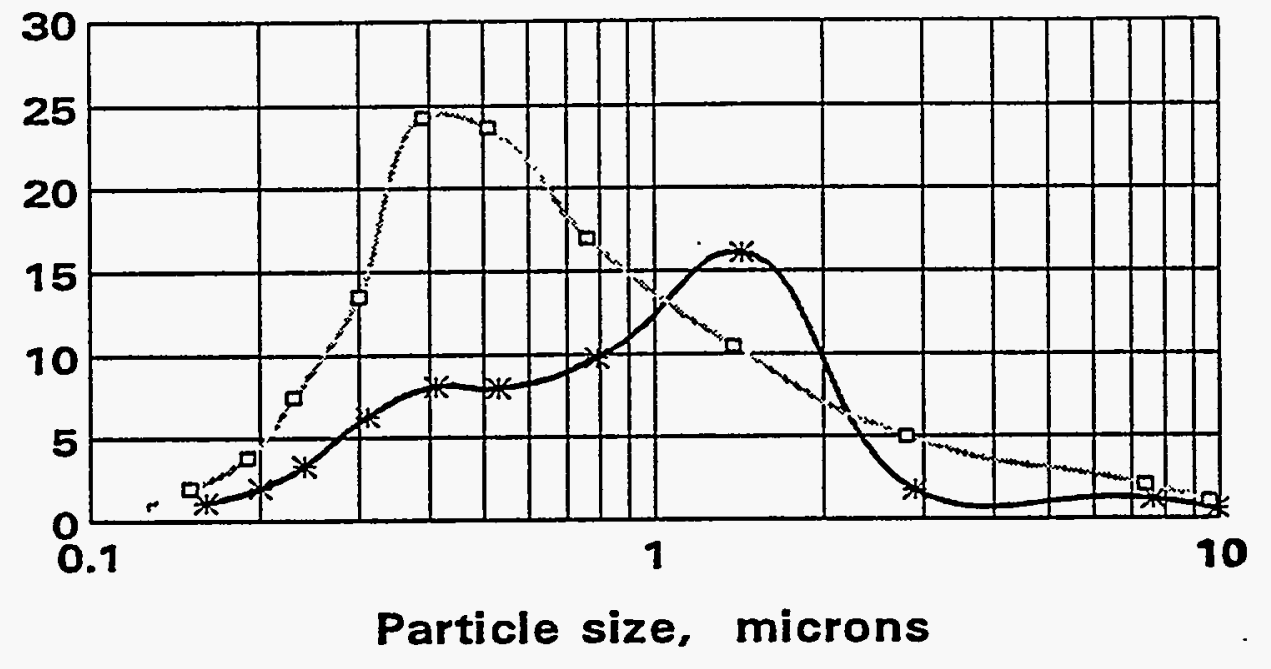

d50, microns $0.54 \quad 0.75$

$\rightarrow$ No Sorbent $*$ Lime

Figure 7. Comparison of Secondary Cyclone Exit Particle Size Distributions

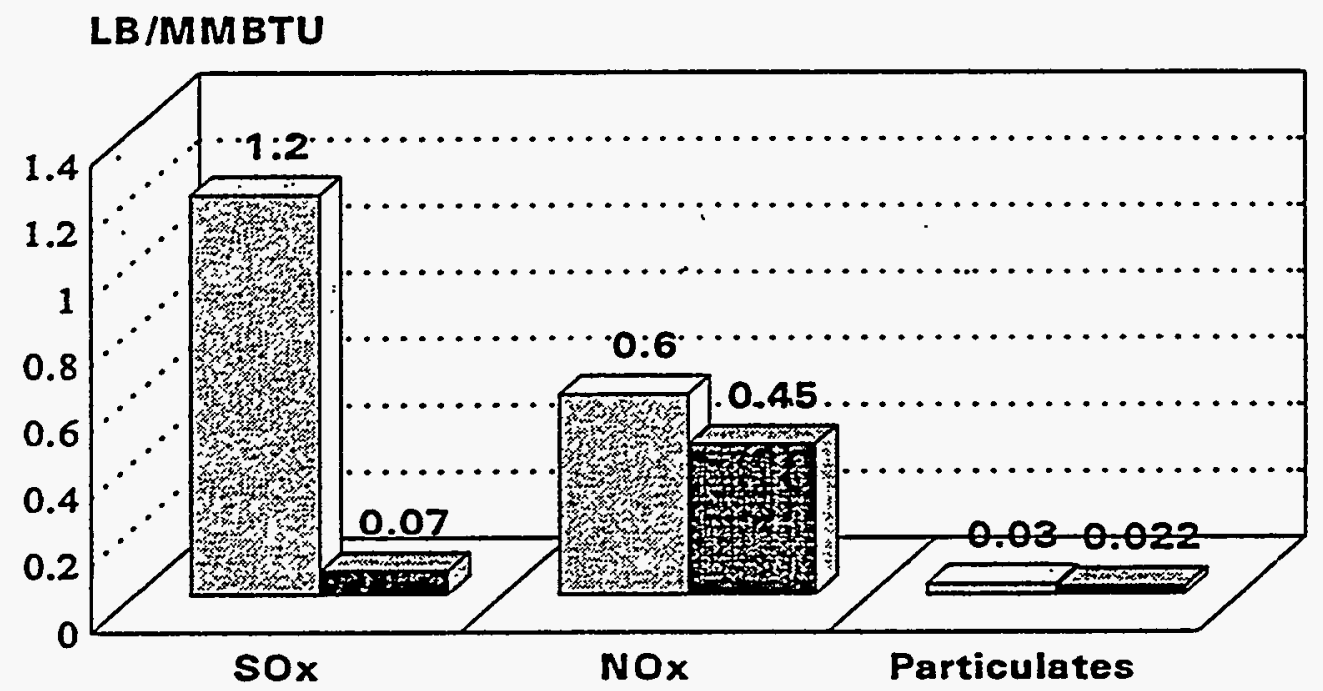

NSPS MTCI TEST RESULTS

Figure 8. Comparison of Measured Emissions with NSPS 


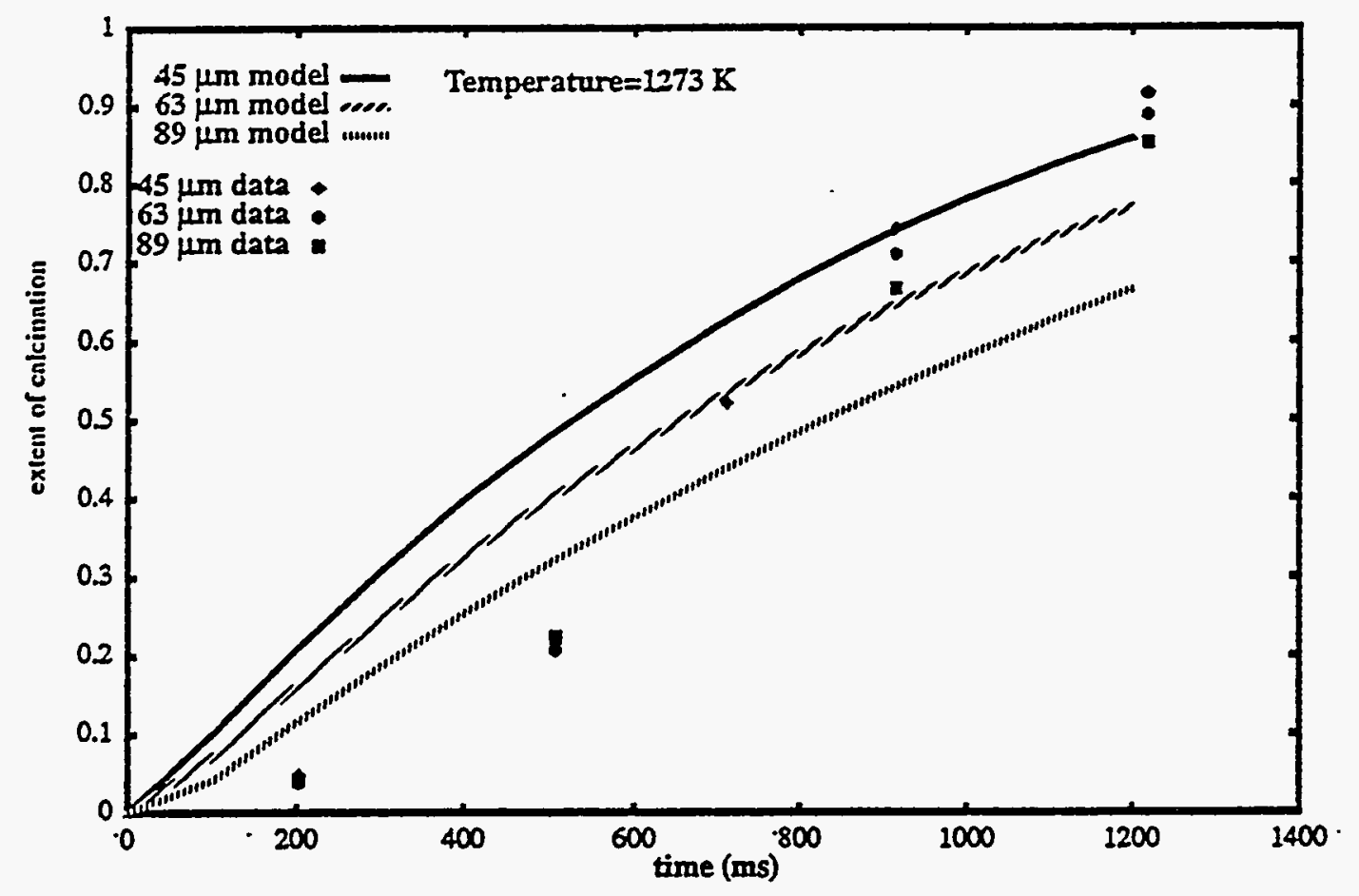

Figure 9. Relationship of Particle Size to the Extent of Calcination with Time

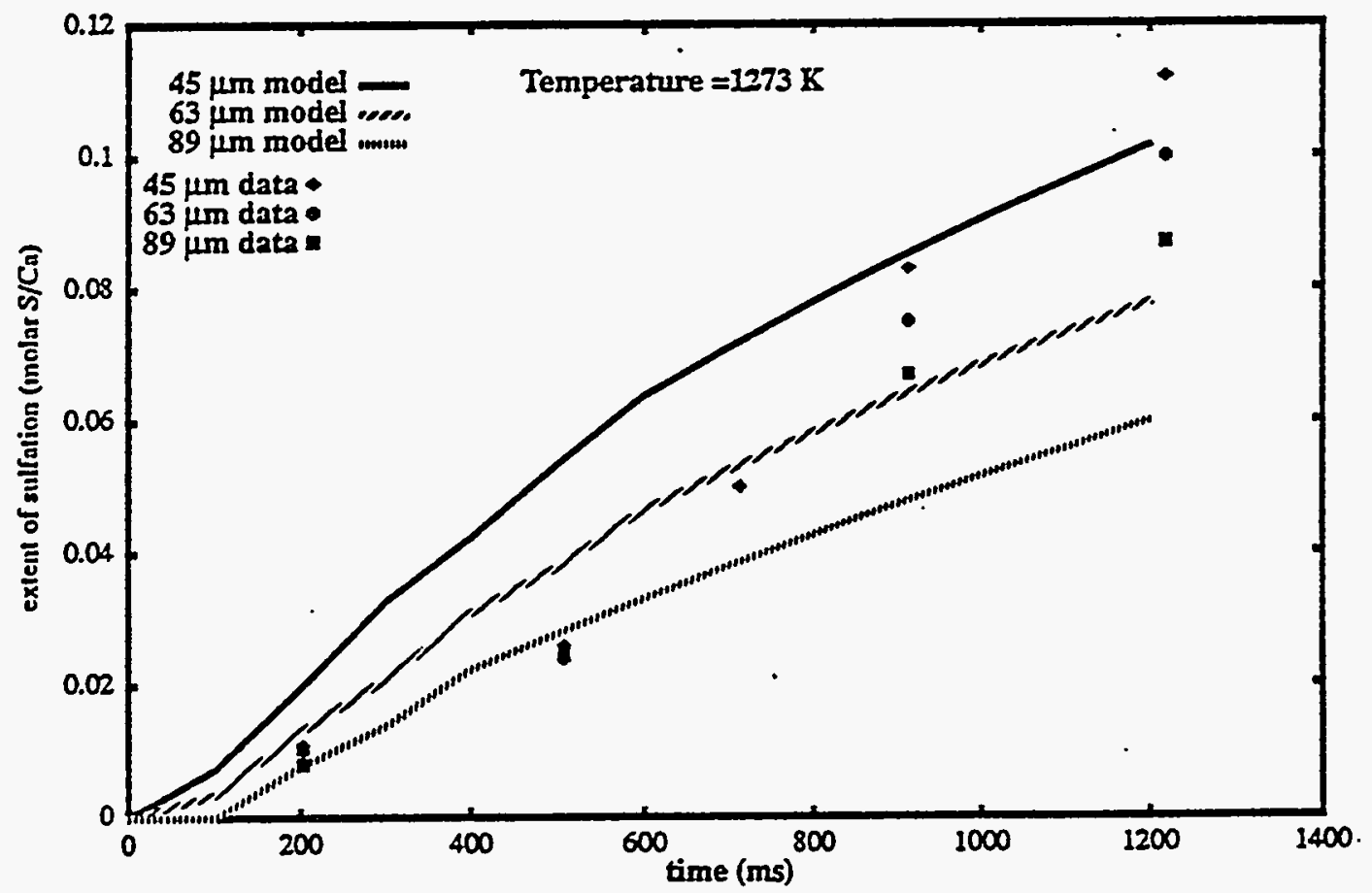

Figure 10. Relationship of Particle Size to the Extent of Sulfation with Time 
Diameter $=100 \mu \mathrm{m}$

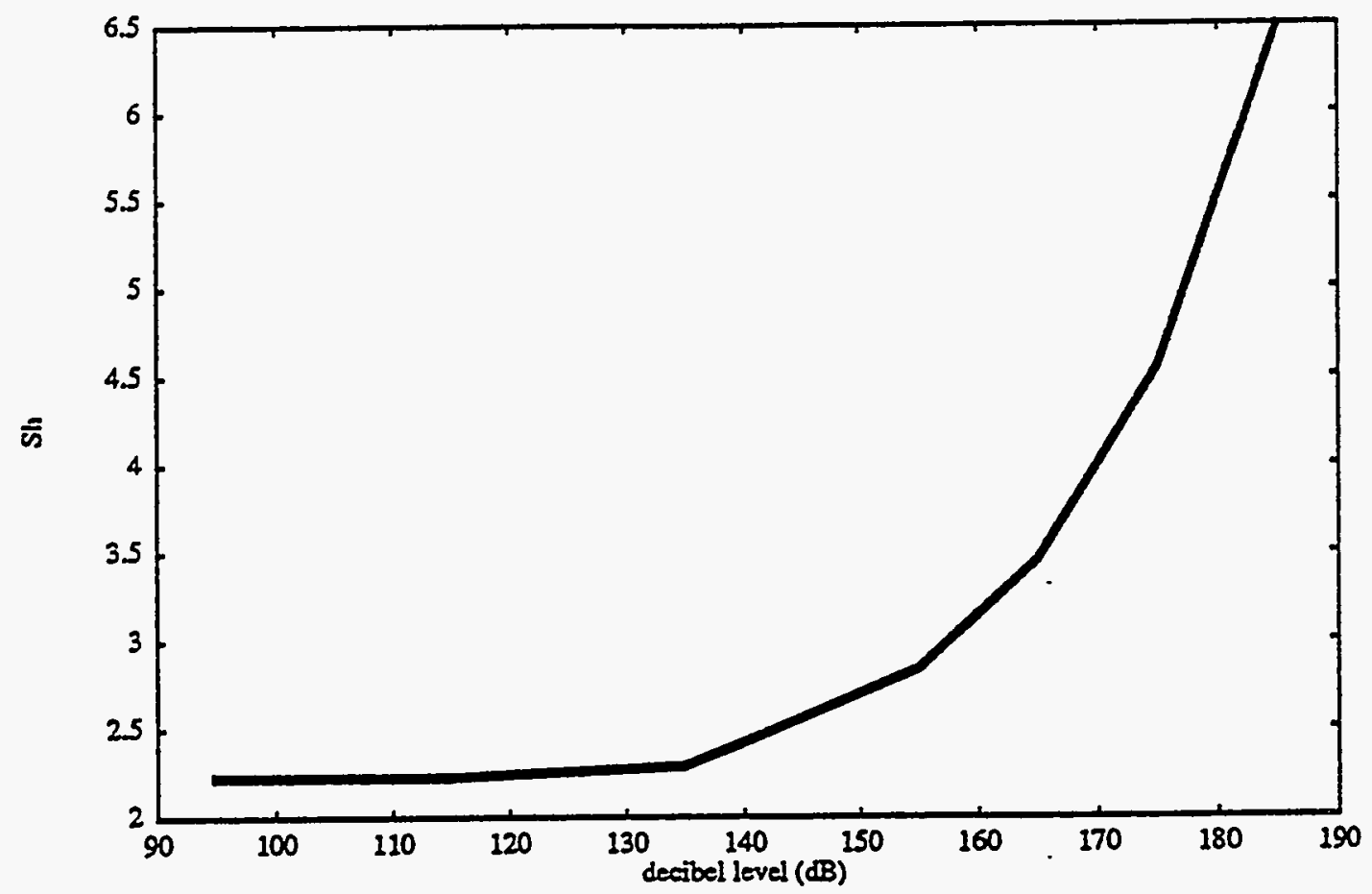

Figure 11. Relationship of Sherwood Number to Sound Pressure (dB)

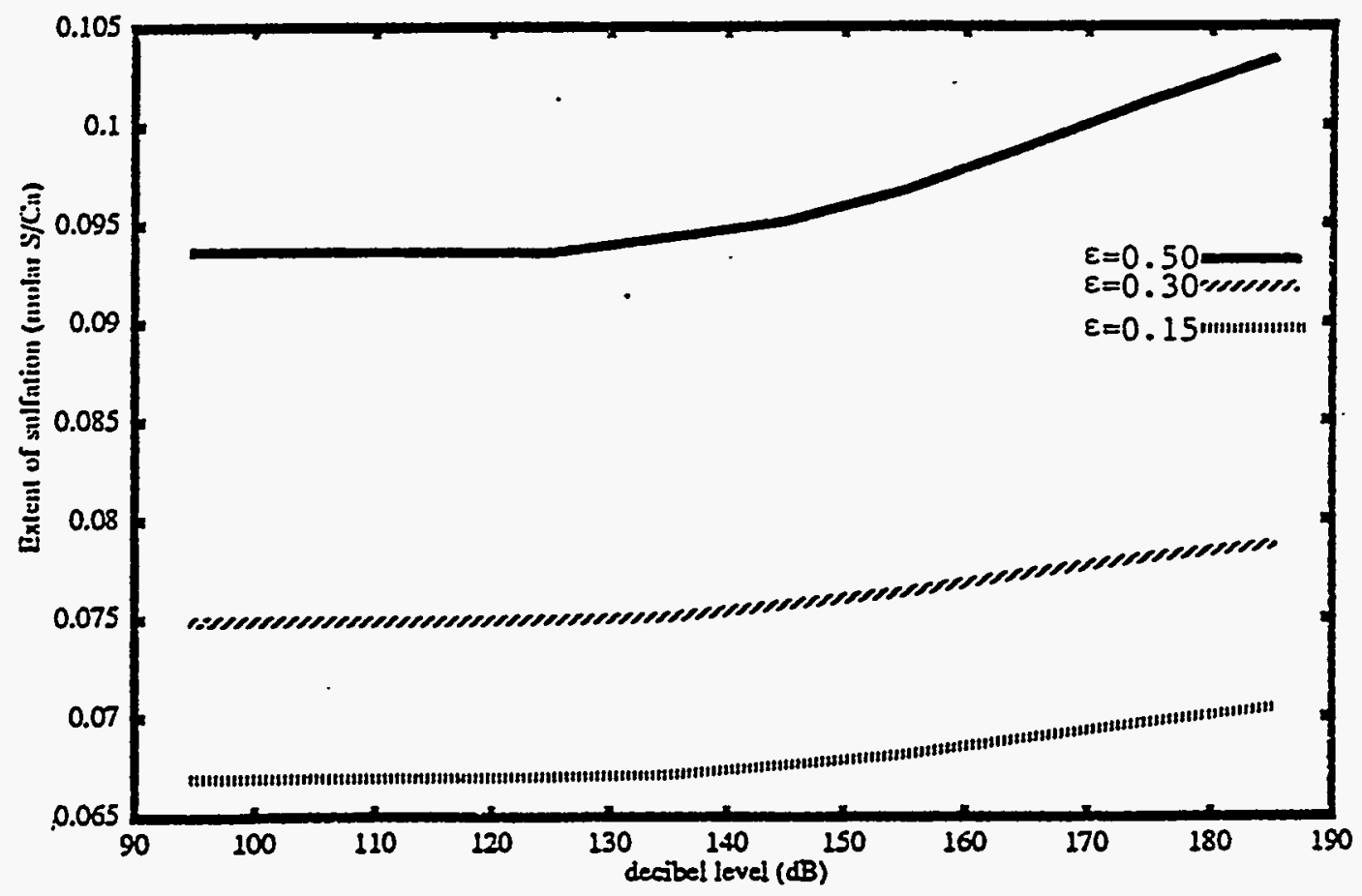

Diameter of sorbent particle $=100 \mu \mathrm{m}$

Figure 12. Relationship of the Extent of Sulfation to Sound Pressure (dB) as a Function of Porosity $(\epsilon)$ 


\section{$\square$ Acoustic Particle Interaction Phenomena}
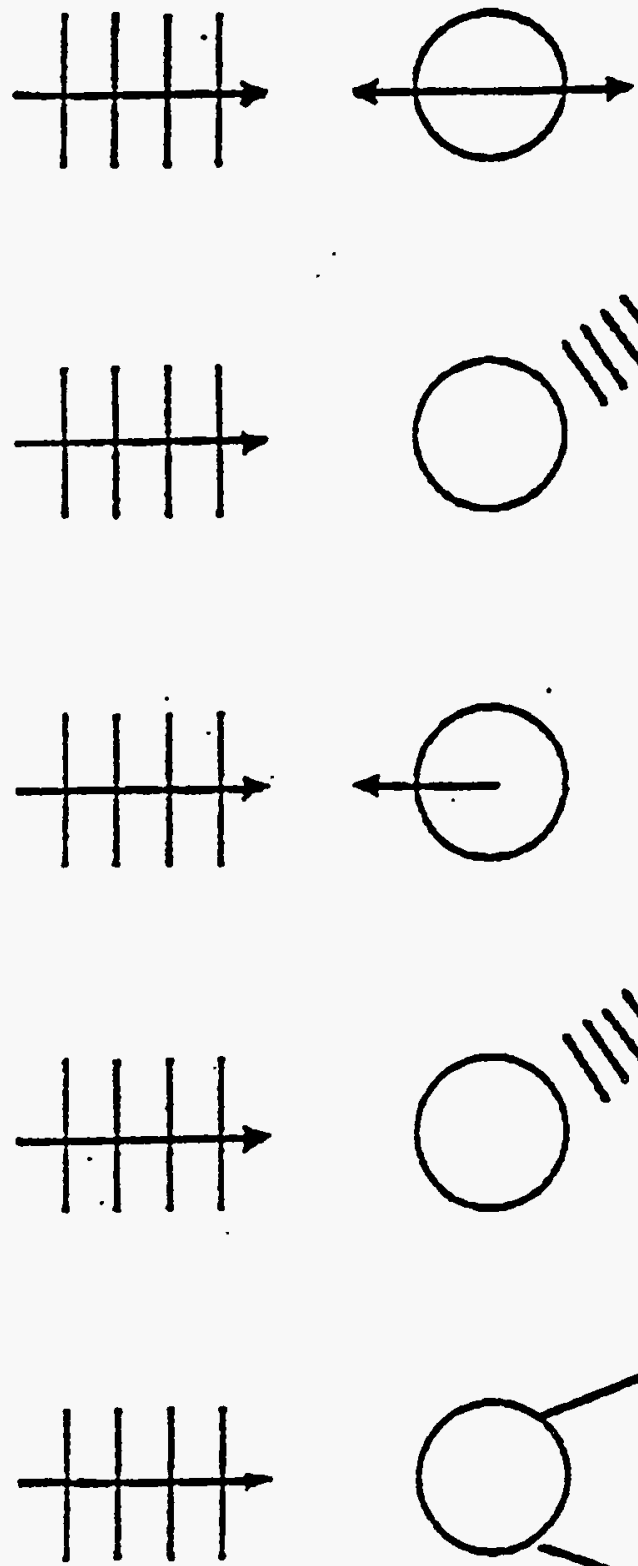

INCOMINO WAYE

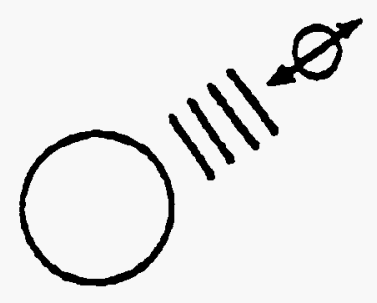

SONG, 1990:

ACOUSTIC ENTRAINMENTT BY THE SCATTERED WAVE linear, multiple parricles

GORKOV, 1962:

ACOUSTICRADIATION

PRESSURE

non-linear, single particle

-DANILOV, MIRONOV, 1984:

MUTUAL ACOUSTIC RADIATION PRESSURES BY THE SCATTERED WAVES non-linear, multipie paricles

PSHENAI-SEVERIN, 1959: ACOUSTIC WAIKE EFFECT DUE TO ASYMMEIRICFLOW FIEIDS non-linear, multiple particles

Figure 13. Theoretical Analysis 


\section{$\square$ Acoustic Wake Effect}

- Caused by Asymmetry of the Flow Field around Moving Particles:

Stokes flow conditions: for dissimilarly sized particles

Oseen flow conditions: for all pairs of particles

- The Trailing Particle Moves in the Wake of the Leading Particle:

drag reduction for the following particle leads to convergent velocity

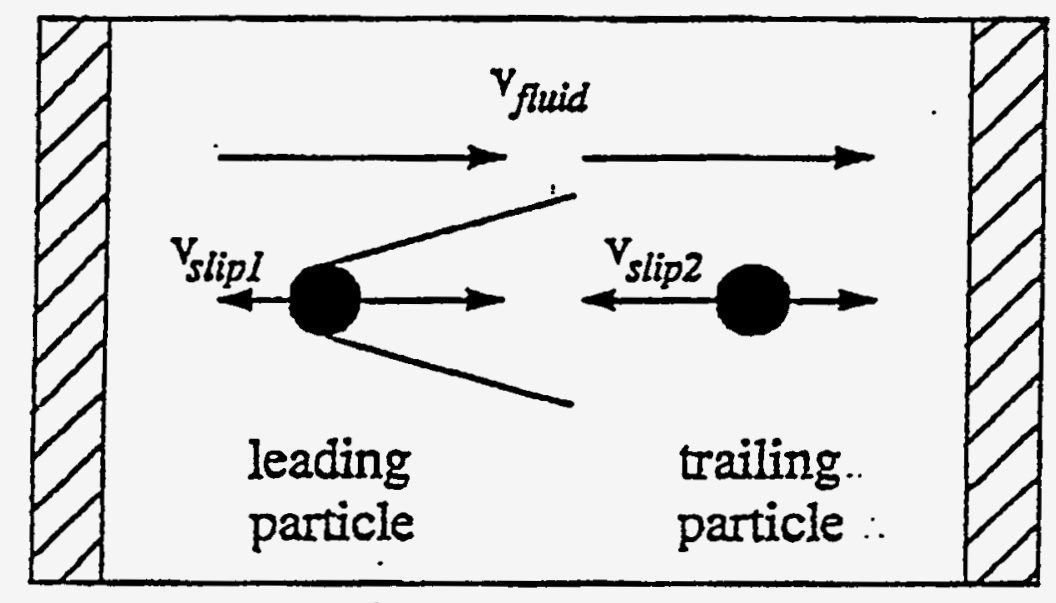

Fluid Velocity in positive $x$-direction

$\mathrm{X}$

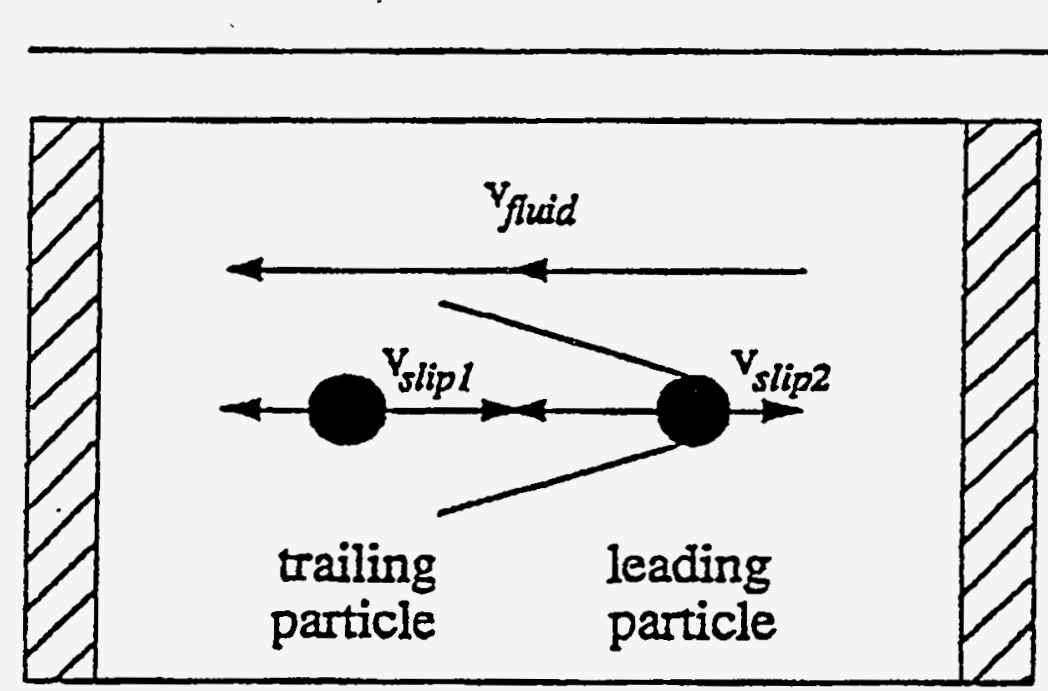

Fluid Velocity in negative $x$-direction

Figure 14. 
Table 1: Summary of Conclusions Regarding Status of Proposed Acoustic Agglomeration Mechanisms

\begin{tabular}{||l|l||}
\hline \hline Orthokinetic Agglomeration & Not Supported \\
\hline Agglomeration Volume and Refill Mechanism & Not Supported \\
\hline Gravitational Effects & $\begin{array}{l}\text { - Important for dissimilar sized particles. } \\
- \text { Disadvantageous for the agglomeration } \\
\text { process. }\end{array}$ \\
\hline Mutual Radiation Pressure Interaction & $\begin{array}{l}\text { Captive force field generated by the interaction } \\
\text { of mutual radiation pressure and acoustic wake } \\
\text { effect explaining the effect of pair building. }\end{array}$ \\
\hline Acoustic Wake Effect & $\begin{array}{l}\text { Dominant interaction mechanism which } \\
\text { accounts for the hydrodynamic agglomerations } \\
\text { observed. }\end{array}$ \\
\hline Tuning Fork Agglomerations & $\begin{array}{l}\text { - The determining mechanism for acoustic } \\
\text { agglomeration of similarly sized particles. } \\
-\begin{array}{l}\text { No agglomeration between dissimilarly } \\
\text { sized particles. }\end{array}\end{array}$ \\
\hline $\begin{array}{l}\text { Very high sound power leads to excessive } \\
\text { dinetic energy of the particles; rebound is } \\
\text { possible during collision. }\end{array}$ \\
\hline
\end{tabular}




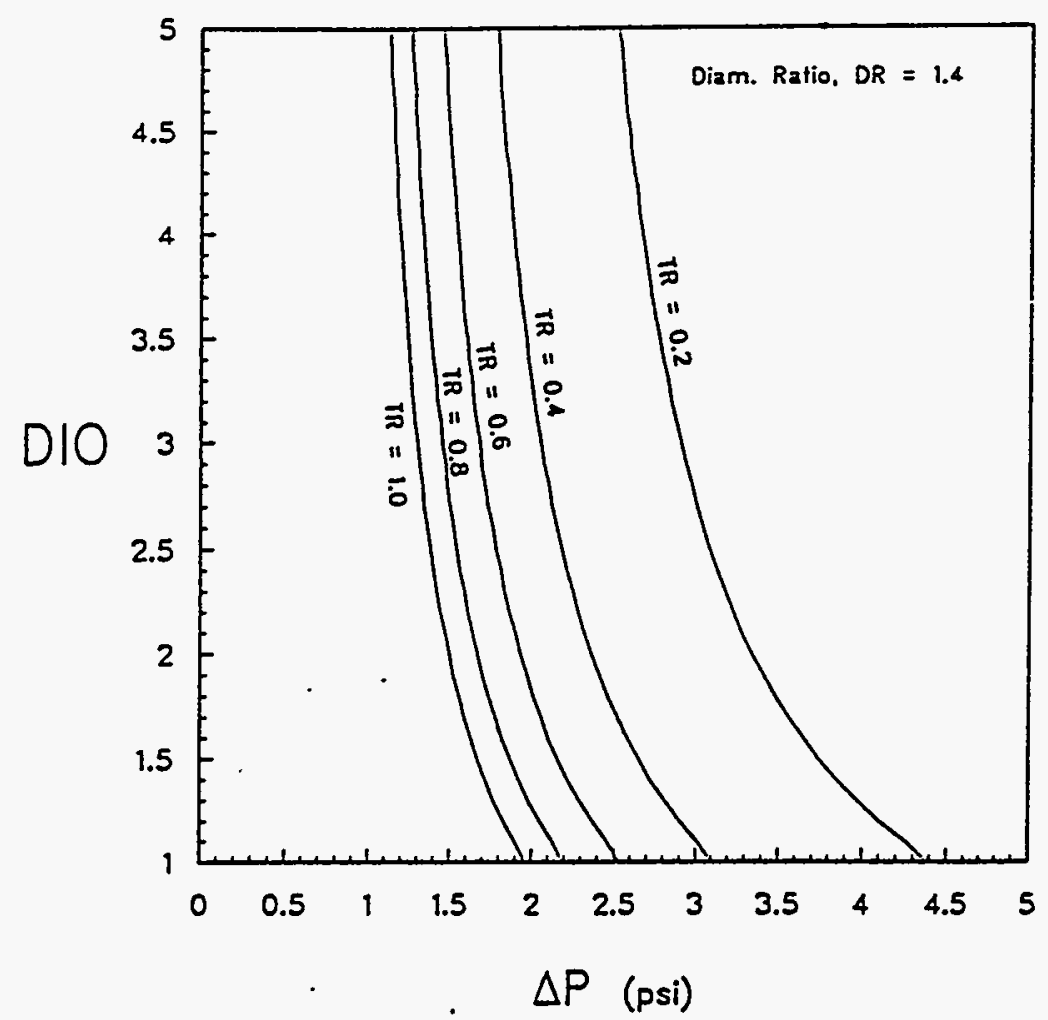

Figure 15. Computed Diodicity vs. $\Delta P$ for Various $T_{R}$

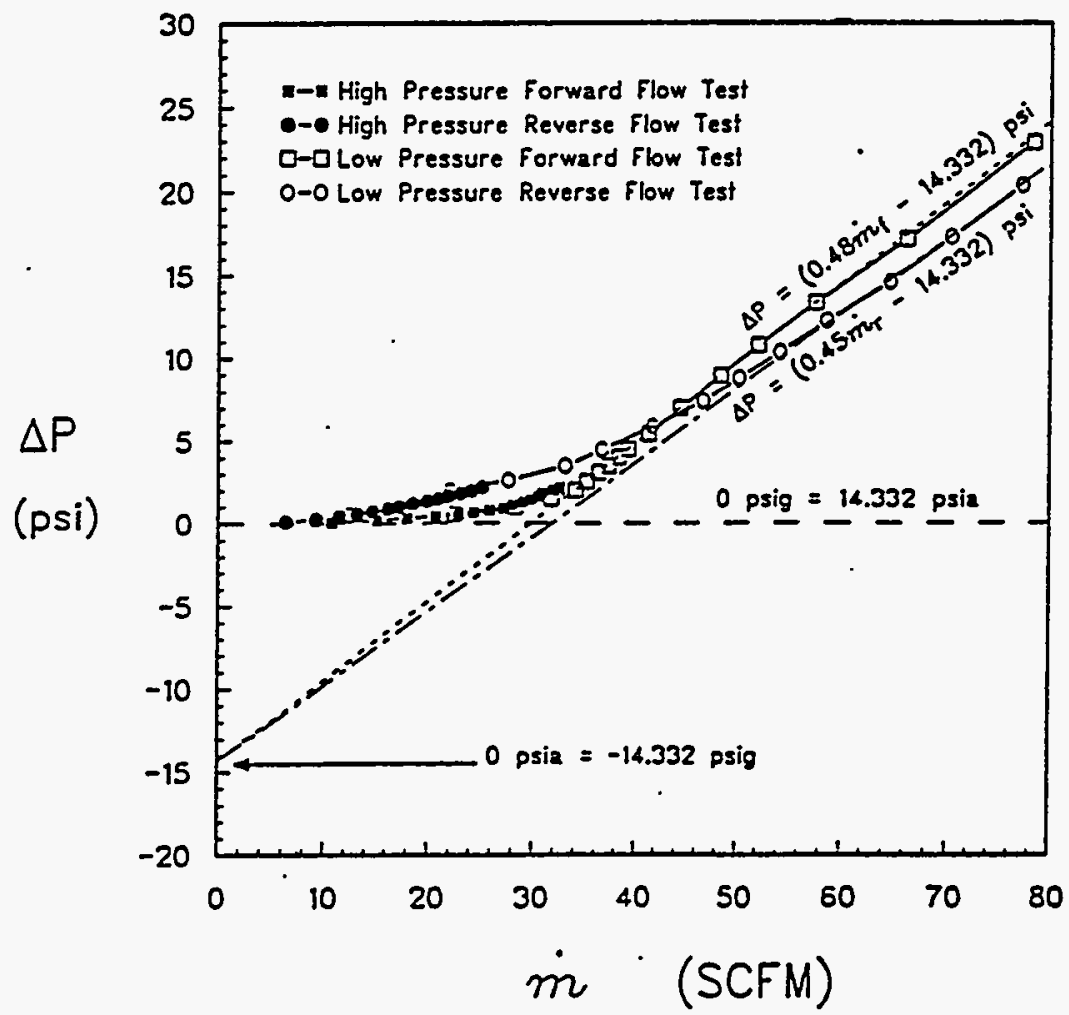

Figure 16. Aerovalve Inlet Pressure Drop vs. Mass Flow 